\title{
Short- and Long-Term Effects of Alkali Therapy in Chronic Kidney Disease: A Systematic Review
}

\author{
Paweena Susantitaphong ${ }^{a, c}$ Kamal Sewaralthahab $^{a}$ Ethan M. Balk ${ }^{b}$ \\ Bertrand L. Jaber $^{a}$ Nicolaos E. Madias ${ }^{a}$ \\ a Division of Nephrology, Kidney and Dialysis Research Laboratory, Department of Medicine, St. Elizabeth's \\ Medical Center and ${ }^{b}$ Center for Clinical Evidence Synthesis, Tufts Clinical and Translational Science Institute, \\ Tufts University, Boston, Mass., USA; ' Extracorporeal Multiorgan Support Dialysis Center, Division of Nephrology, \\ Department of Medicine, King Chulalongkorn Memorial Hospital, Faculty of Medicine, Chulalongkorn University, \\ Bangkok, Thailand
}

\section{Key Words}

Bicarbonate therapy $\cdot$ Chronic kidney disease $\cdot$

Meta-analysis

\begin{abstract}
Background: Clinical practice guidelines recommend alkali therapy in patients with non-dialysis-dependent chronic kidney disease (CKD) and metabolic acidosis to prevent complications from metabolic acidosis. We systematically reviewed the effect of sodium bicarbonate on benefits and harms in patients with CKD. Methods: We searched for randomized controlled trials in MEDLINE (through July 2011), Cochrane Central Register of Controlled Trials, ClinicalTrials. gov, and scientific abstracts. We included trials that compared sodium bicarbonate to standard-of-care therapy or placebo that reported on kidney-related outcomes. We performed random-effects model meta-analyses to compute net changes (for continuous variables) and risk ratios (for binary variables). Results: Two short-term ( $\leq 7$ days) crossover trials and 4 long-term ( $\geq 2$ months) parallel-design randomized controlled trials met eligibility (312 patients). All 6 trials prescribed sodium bicarbonate in the alkali-treated group. In the long-term studies, alkali therapy was associated with
\end{abstract}

a net decrease in serum creatinine $(-0.07 \mathrm{mg} / \mathrm{dl}, 95 \% \mathrm{Cl}$ $\left.-0.09,-0.05 ; \mathrm{p}<0.001 ;\left.\right|^{2}=0\right)$, a net improvement in GFR (3.2 $\mathrm{ml} / \mathrm{min} / 1.73 \mathrm{~m}^{2}, 95 \% \mathrm{Cl} 1.6,4.7 ; \mathrm{p}<0.001 ; \mathrm{I}^{2}=0$ ), and a lower incidence of dialysis initiation (risk ratio $0.21,95 \% \mathrm{Cl} 0.08$, $0.54 ; p=0.001 ; I^{2}=0$ ). No benefit was observed on the serum creatinine or GFR in short-term studies. Alkali therapy was not associated with a higher likelihood of initiating or escalating anti-hypertensive medications. Conclusions: Alkali therapy is associated with an improvement in kidney function, which may afford a long-term benefit in slowing the progression of CKD. However, differences in study protocols and small sample sizes preclude definitive conclusions.

Copyright $\odot 2012$ S. Karger AG, Basel

\section{Introduction}

Metabolic acidosis is one of the most commonly encountered complications of chronic kidney disease (CKD), especially among patients with an estimated glomerular filtration rate (eGFR) $<25 \mathrm{ml} / \mathrm{min} / 1.73 \mathrm{~m}^{2}[1]$. Clinical practice guidelines recommend initiation of alkali therapy when the serum bicarbonate level is $<22$ $\mathrm{mEq} / \mathrm{l}$ to prevent or treat complications of metabolic aci-

\section{KARGER}

Fax +4161306 1234 E-Mail karger@karger.ch www.karger.com
(C) 2012 S. Karger AG, Basel

0250-8095/12/0356-0540\$38.00/0

Accessible online at:

www.karger.com/ajn
Nicolaos E. Madias, MD, FASN

St. Elizabeth's Medical Center

736 Cambridge Street, Boston, MA 02135 (USA)

Tel. +1 6175627830

E-Mail nicolaos.madias@steward.org 
dosis [2], including growth retardation in children, exacerbation of bone disease, increased muscle degradation with resulting frailty, reduced albumin synthesis, and increased inflammation [3].

Alkali therapy has been shown to retard the progression of CKD in several animal studies [4-6] but the effect has not been consistent $[7,8]$. Notwithstanding, a limited number of human studies has supported a beneficial role of alkali administration on the course of CKD [9-12]. A previous systematic review on the correction of metabolic acidosis restricted to patients with stage $5 \mathrm{CKD}$ on long-term dialysis identified 3 trials totaling 117 participants; it suggested some beneficial effects of such correction on both protein and bone metabolism in patients with stage 5 CKD on long-term dialysis [13]. However, that systematic review was inconclusive on the potential benefits of alkali therapy on changes in GFR in earlier stages of CKD [13]. The potential harms of alkali therapy in patients with CKD include extracellular fluid volume expansion with resulting development or aggravation of hypertension, and decompensation of heart failure. As part of the Kidney Research National Dialogue, an interactive web-based dialogue initiated by the National Institutes of Health, alkali therapy was identified as a potentially effective treatment strategy to retard progression of CKD [14]. However, before alkali therapy can be recommended as part of the armamentarium to slow progression of CKD, definitive studies on its potential benefits and risks need to be carried out. To summarize the available evidence, inform clinical practice, and provide future research directions, we performed a systematic review with meta-analyses of trials examining the shortand long-term effects of alkali therapy in patients with CKD (not on dialysis), as compared to standard-of-care therapy or placebo.

\section{Methods}

\section{Data Sources and Search Strategy}

We searched Medline (inception: July 2011) using the following MeSH database search terms: 'acidosis', 'metabolic acidosis', 'acid-base imbalance', 'acid-base status', 'bicarbonate', 'sodium bicarbonate', 'sodium citrate', 'alkaline buffer', 'renal insufficiency', 'kidney disease', 'chronic renal failure', and 'chronic kidney disease'. The search strategy was limited to human trials with no language restrictions. We also searched the Cochrane Central Register of Controlled Trials, and ClinicalTrials.gov for completed trials using similar search terms, reviewed the American Society of Nephrology scientific abstracts (2003-2010 annual meetings), and performed manual searches of references in narrative and systematic reviews on alkali therapy.

\section{Study Selection}

We included crossover and parallel-design randomized controlled trials of children and adults with CKD not requiring dialysis that compared the short- and long-term effects of alkali therapy versus standard-of-care or placebo. We allowed any form of alkali therapy, including but not limited to sodium bicarbonate.

We evaluated the following effects of alkali therapy: changes in serum levels of bicarbonate, sodium, potassium, chloride, urea nitrogen, creatinine, and albumin; changes in body weight, and systolic and diastolic blood pressure; changes in 24-hour urine sodium and protein excretion, and GFR. We included GFR measurements that were either estimated using the Modification of Diet in Renal Disease (MDRD) study equation or calculated using the creatinine clearance derived from a 24 -hour urine collection. Other outcomes of interest included the proportion of patients that required the initiation or escalation of anti-hypertensive agents (e.g. diuretics), and the initiation of dialysis.

If more than one publication appeared on the same study, data from the most inclusive report were used. Some of the trials reported data over 4-7 days of intervention. Other studies reported data over 2-60 months of intervention. Therefore, we arbitrarily defined short-term studies as $\leq 7$-day duration and long-term studies as $\geq 2$-month duration.

\section{Data Extraction and Quality Assessment}

Two of the authors (P.S. and K.S.) independently reviewed and screened the titles and abstracts of the electronic citations and the scientific abstracts. Potentially relevant full-text articles were retrieved for comprehensive review and re-screened. Data extracted from full-text articles included the following: country of origin, year of publication, study design, number of patients, and cohort characteristics, including mean age, percentage of men and diabetics, baseline mean GFR, target serum bicarbonate level, alkali therapy type, administration route and dose, and duration of intervention. Disagreements were resolved through consensus and arbitration by a third author (B.L.J.). Corresponding authors of trials were contacted for additional information. Study quality was assessed using a modified Jadad scale $[15,16]$ with a higher score reflecting better quality.

\section{Data Synthesis and Analysis}

Random-effects model meta-analyses [17] were performed to assess the net change (with $95 \%$ confidence interval (CI)) in all of the aforementioned continuous outcome variables in the alkalitreated group relative to the control group. For the assessment of change in GFR, creatinine clearance and eGFR (reported in $\mathrm{ml} / \mathrm{min}$ and $\mathrm{ml} / \mathrm{min} / 1.73 \mathrm{~m}^{2}$, respectively) were assumed to be equivalent and modeled together. Random-effect model metaanalyses were also performed to assess the risk ratio (RR) (with 95\% CI) for the initiation or escalation of anti-hypertensive agents, and for dialysis requirement in the alkali-treated group relative to the control group. The analyses were stratified a priori according to the duration of intervention ( $\leq 7$ days vs. $\geq 2$ months, see above).

The heterogeneity across effect sizes of individual trials was assessed using the $\mathrm{I}^{2}$ index and the $\mathrm{Q}$ test $\mathrm{p}$ value. Publication bias was formally assessed using funnel plots and the Egger test. The analyses were performed using Comprehensive Meta-Analysis version 2.0 and forest plots were drawn with the metan command of Stata 11.2 (College Station, Tex., USA). 


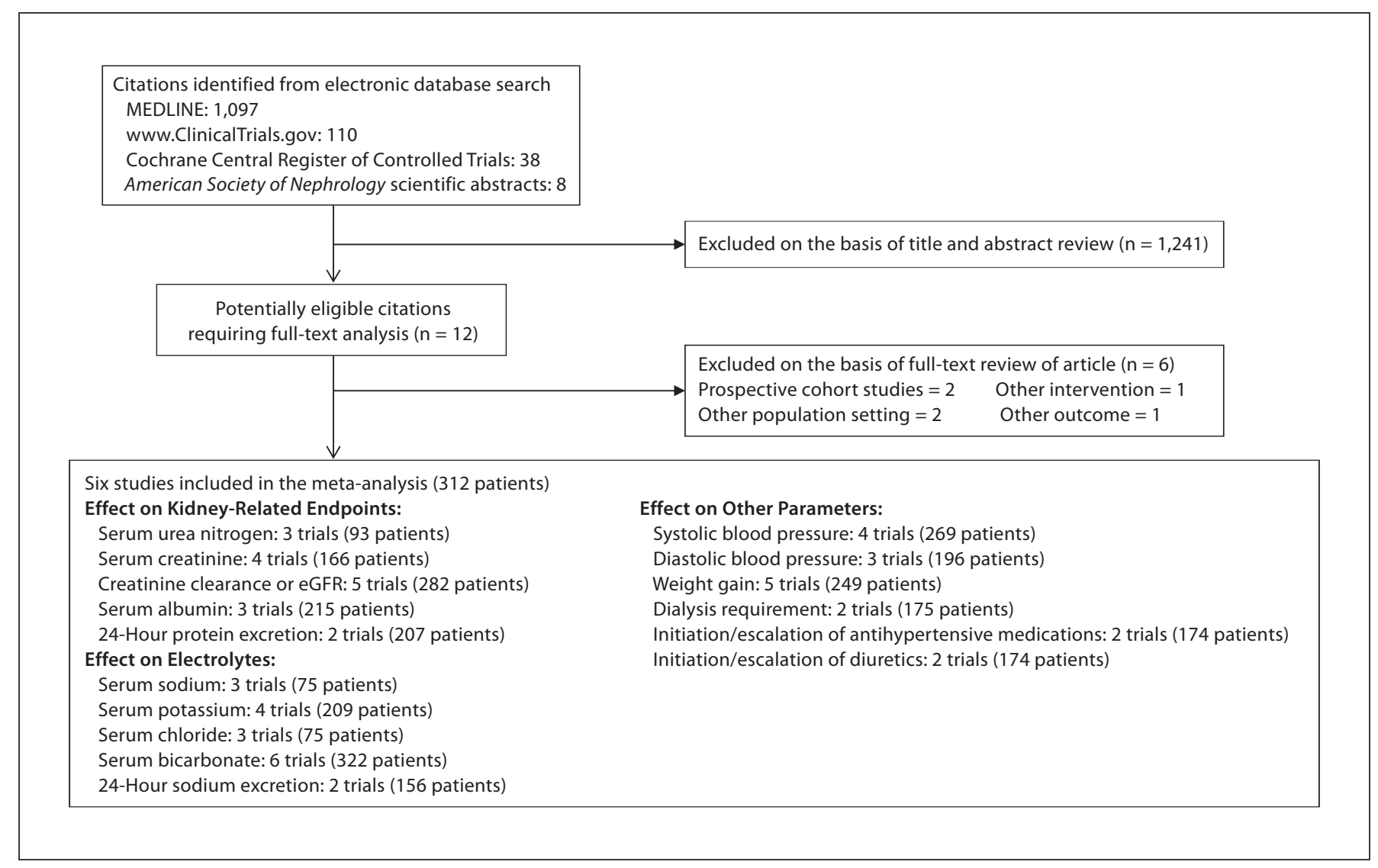

Fig. 1. Study selection flow diagram.

\section{Results}

\section{Characteristics and Quality of the Studies}

A total of 1,253 potentially relevant citations were identified and screened; 12 articles were retrieved for detailed evaluation, of which 6 fulfilled eligibility criteria (fig. 1) [10, 11, 18-21]. Three out of 4 corresponding authors of trials who were contacted provided additional information [10, 11, 21].

Characteristics of the individual trials are displayed in table 1 . The publication of studies spanned more than 30 years, and varied widely in sample size (6-134 patients). There were 2 randomized crossover trials and 4 randomized parallel-design trials. The crossover trials were of short duration (4-7 days) and the parallel-design trials were of longer duration (2-60 months). Five of the 6 trials had a predominance of men (range of 51-67\%) with a mean age of participants ranging from 41 to 63 years. The GFR was calculated in 3 studies, estimated in 2 studies, and was not reported in 1 study. Mean baseline GFR (cre- atinine clearance or eGFR) ranged from $13 \mathrm{ml} / \mathrm{min}$ to 20 $\mathrm{ml} / \mathrm{min} / 1.73 \mathrm{~m}^{2}$ in 4 of the 5 studies reporting GFR and $75 \mathrm{ml} / \mathrm{min} / 1.73 \mathrm{~m}^{2}$ in the fifth. In 5 of the 6 trials where alkali therapy was used to treat metabolic acidosis of advanced $C K D$, the mean serum bicarbonate level at enrollment was $<22 \mathrm{mEq} / \mathrm{l}$, ranging between 19.4 and 21.4 $\mathrm{mEq} / \mathrm{l}$. In the sixth trial where alkali therapy was prescribed to patients with earlier stages of CKD, the baseline mean serum bicarbonate level was $26.3 \mathrm{mEq} / \mathrm{l}$. Sodium bicarbonate was prescribed in the alkali-treated group in all the trials, whereas glucose, sodium chloride, a small dose of sodium bicarbonate, or standard care was prescribed in the control groups. Study quality was considered poor (score of $0-1$ ) in 2 trials $[18,20]$, fair (score of 2-3) in 3 trials $[11,19,21]$, and good (score of 4-5) in 1 trial [10].

\section{Effect of Alkali Therapy on Kidney-Related Endpoints}

Table 2 summarizes the effects of alkali therapy according to duration of intervention. As shown in Figure 


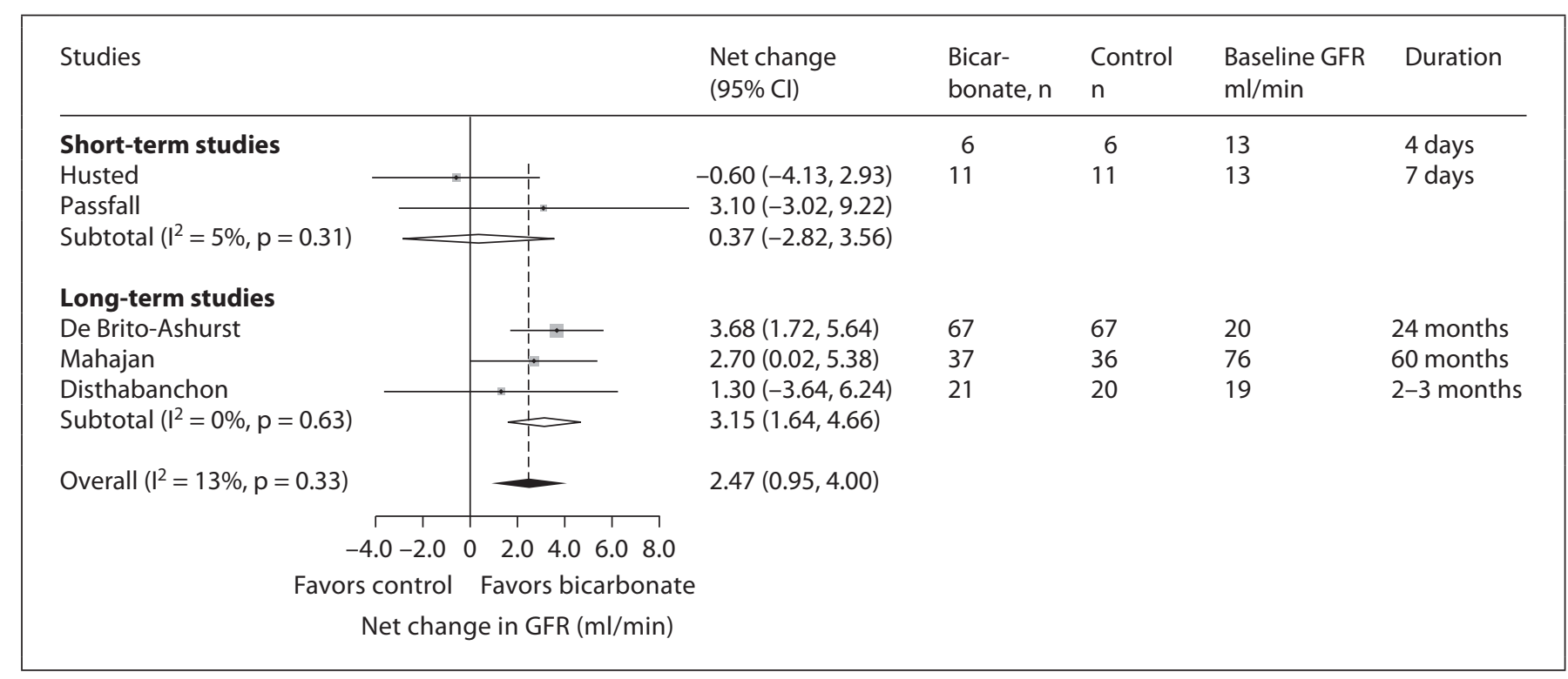

Fig. 2. Forest plot displaying the effect of bicarbonate therapy in patients with CKD on change in GFR ( $\mathrm{ml} / \mathrm{min}$ or $\mathrm{ml} / \mathrm{min} / 1.73 \mathrm{~m}^{2}$ ).

2 , in the 3 long duration trials (248 patients), alkali therapy was associated with a significant net improvement in GFR of $3.2 \mathrm{ml} / \mathrm{min} / 1.73 \mathrm{~m}^{2}\left(95 \%\right.$ CI $1.6,4.7 ; \mathrm{p}<0.001 ; \mathrm{I}^{2}$ $=0 \%)$. Such an effect was not observed in the 2 short-term studies (34 patients).

Similarly, in the 3 long duration trials (154 patients), alkali therapy resulted in a significant net decrease in serum creatinine of $0.07 \mathrm{mg} / \mathrm{dl}(95 \% \mathrm{CI}-0.09,-0.05$; p < $\left.0.001 ; \mathrm{I}^{2}=0 \%\right)$. In an analysis of 2 long-term studies (81 patients), alkali therapy was associated with a significant net decrease in serum urea nitrogen of $10.8 \mathrm{mg} / \mathrm{dl}(95 \%$ CI $\left.-17.5,-4.1 ; \mathrm{p}=0.002 ; \mathrm{I}^{2}=32 \%\right)$. Such effects were not observed in short-term studies.

In an analysis of 2 long-term studies (278 patients), there was no demonstrable effect of alkali therapy on 24hour urine protein excretion. Such data were not available in short-term studies.

Finally, analysis of 2 long-term studies (175 patients, not shown in table 2) revealed that the alkali-treated group experienced a 79\% risk reduction in the incidence of dialysis requirement as compared to the control group (RR 0.21, 95\% CI 0.08, 0.54; $\mathrm{p}=0.001 ; \mathrm{I}^{2}=0 \%$ ).

\section{Effect of Alkali Therapy on Electrolytes}

As shown in table 2 , in the 2 short-term studies (34 patients), alkali therapy was associated with a significant net increase in the serum bicarbonate concentration of
$5.4 \mathrm{mEq} / \mathrm{l}\left(95 \% \mathrm{CI} 4.0,6.7 ; \mathrm{p}<0.001 ; \mathrm{I}^{2}=0 \%\right)$. A significant net increase in the serum bicarbonate concentration was also observed in long-term studies (4 studies, $288 \mathrm{pa}-$ tients) that averaged $2.7 \mathrm{mEq} / \mathrm{l}(95 \% \mathrm{CI} 0.6,4.8 ; \mathrm{p}=0.013$; $\left.\mathrm{I}^{2}=97 \%\right)$.

Conversely, significant net decreases in the serum chloride concentration were observed, which averaged $8.0 \mathrm{mEq} / \mathrm{l}\left(95 \% \mathrm{CI}-10.4,-5.6, \mathrm{p}<0.001 ; \mathrm{I}^{2}=0 \%\right)$ in shortterm studies, and $2.1 \mathrm{mEq} / 1(95 \% \mathrm{CI}-3.5,-0.6 ; \mathrm{p}=0.006$; $\mathrm{I}^{2}=0 \%$ in long-term studies. Alkali therapy was associated with a significant net decrease in the serum potassium concentration in long-term studies (2 studies, 175 patients) that averaged $0.7 \mathrm{mEq} / \mathrm{l}(95 \% \mathrm{CI}-1.3,-0.1 ; \mathrm{p}=$ $0.03 ; \mathrm{I}^{2}=95 \%$ ) but no significant change was observed in short-term studies. There were no significant changes in serum sodium concentration in either short- or longterm studies. Only in short-term studies was alkali therapy associated with a significant net increase in 24-hour urine sodium excretion.

\section{Effect of Alkali Therapy on Other Parameters}

As depicted in table 2, alkali therapy had no significant effect on systolic and diastolic blood pressure as well as serum albumin level and body weight (two nutritional indicators) in both short- and long-term studies. Further, alkali therapy was not associated with a higher likelihood for the initiation or escalation of anti-hypertensive med- 


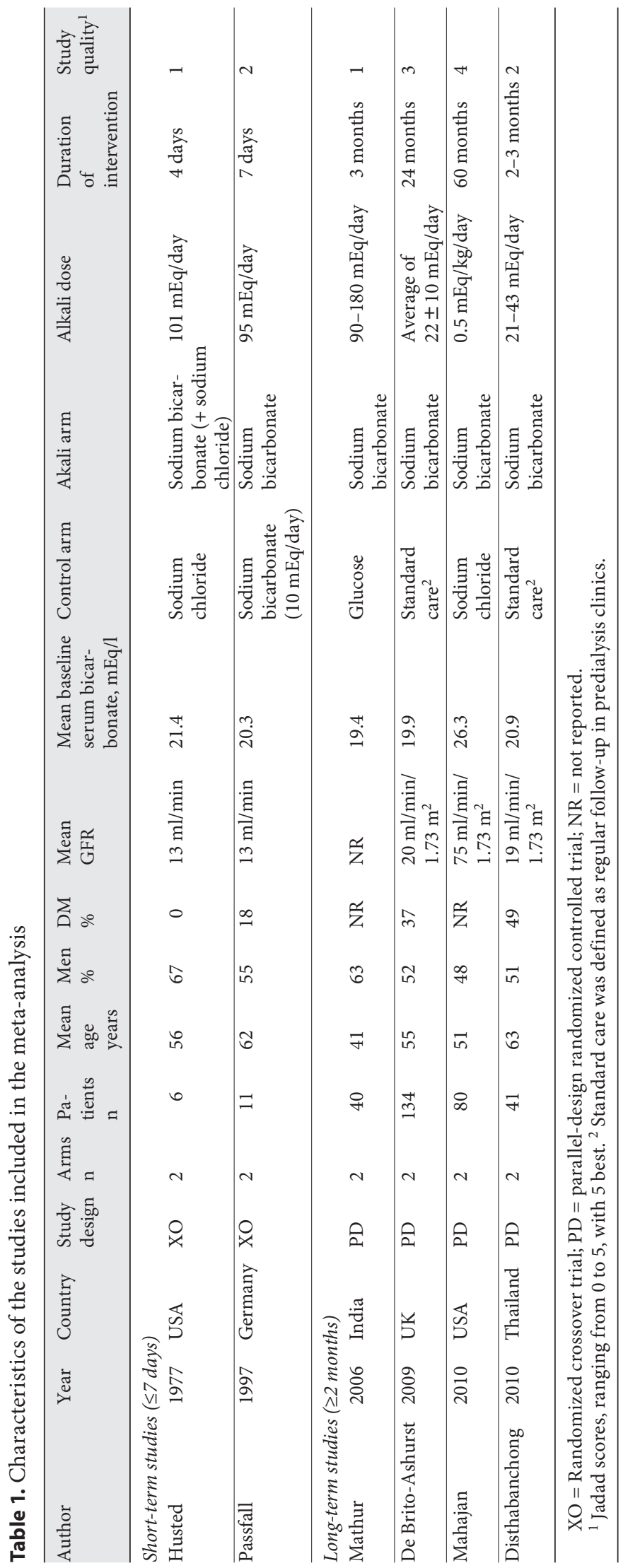

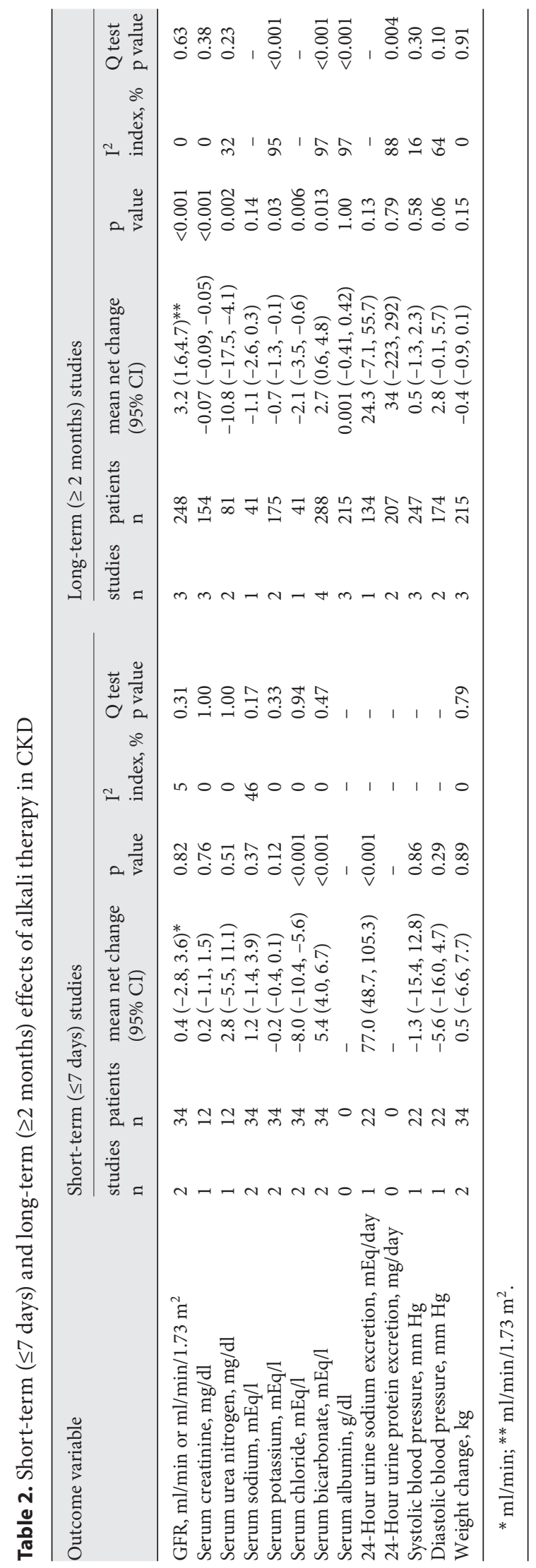

Susantitaphong/Sewaralthahab/Balk/ Jaber/Madias 
ications (174 patients, RR 1.58, 95\% CI 0.53, 4.74; $p=0.41$ ), including diuretics (174 patients, RR 1.34, 95\% CI 0.83, 2.16; $\mathrm{p}=0.23$ ).

Funnel plots of changes in creatinine clearance, serum urea nitrogen, serum creatinine, and serum electrolytes were symmetric and associated with a non-significant Egger test (data not shown) suggesting no publication bias.

\section{Discussion}

In the present systematic review, we summarize the limited available evidence on the short- and long-term effects of alkali therapy in patients with CKD on GFR and other kidney-related endpoints, as well as electrolytes and other parameters. Our main finding is a long-term favorable effect of alkali therapy on GFR preservation and decreased dialysis requirement. This effect was not associated with an adverse impact on blood pressure, including initiation or escalation of anti-hypertensive medications, such as diuretics.

The annual age-related decline in GFR after the age of 40 is $0.75-1.0 \mathrm{ml} / \mathrm{min} / 1.73 \mathrm{~m}^{2}$ [22], with steeper declines of $>4 \mathrm{ml} / \mathrm{min} / 1.73 \mathrm{~m}^{2}$ annually in patients with CKD qualifying as fast progression [23]. Our analysis revealed a net improvement in GFR of $3.2 \mathrm{ml} / \mathrm{min} / 1.73 \mathrm{~m}^{2}$ and a $79 \%$ risk reduction in the incidence of dialysis requirement by alkali therapy over the time span of the longterm trials. These results have potentially important implications for the clinical course of patients with CKD and the economics of end-stage kidney disease programs.

The results of our meta-analysis are in agreement with those of previous experimental studies. Administration of sodium bicarbonate to rats with subtotal nephrectomy attenuated the degree of tubulointerstitial disease compared with controls administered sodium chloride [5]. Similarly, administration of sodium bicarbonate to Han:SPRD rats, an experimental model of polycystic kidney disease, markedly reduced the progression of cystic disease and the severity of interstitial inflammation in comparison with animals administered sodium chloride [6]. These salutary effects were attributed to a reduction in renal ammoniagenesis or consequences thereof; it was postulated that high ammonia generation causes renal injury by activating the alternate complement pathway $[5$, 6]. Further, administration of calcium citrate, a source of alkali, to subtotally nephrectomized rats diminished the glomerular and tubulointerstitial damage and markedly attenuated the decrease in GFR [4]. However, discordant results were obtained in another study of the same experimental model, in which sodium bicarbonate did not improve the interstitial injury or renal dysfunction [7]. Also, administration of ammonium chloride to rats with renal failure ingesting a high-phosphate diet actually slowed the progression of renal dysfunction, an effect attributed to decreased precipitation of calcium phosphate in the kidney [8]. Discordant results might variably reflect, at least in part, differences in study design, experimental models, dietary intake, and length of follow-up.

The National Kidney Foundation Kidney Disease Outcomes Quality Initiative and the Care of Australians with Renal Impairment clinical practice guidelines recommend correcting the serum bicarbonate to $>22 \mathrm{mEq} / 1$ to prevent potential adverse effects related to chronic metabolic acidosis, including bone disease and malnutrition $[2,24]$. These recommendations are based on expert opinion rather than the outcomes of sufficiently powered randomized controlled trials. Notwithstanding, a small nonrandomized trial in patients with hypertensive nephropathy and an eGFR averaging $33 \mathrm{ml} / \mathrm{min}$ revealed that treatment with sodium citrate for 2 years slowed the decline in GFR as estimated from both serum creatinine concentrations and serum cystatin $\mathrm{C}$ levels [9]. In that study, urine endothelin-1 excretion, a surrogate of kidney endothelin production, fell in patients treated with sodium citrate. Acidosis-induced upregulation of the endothelin gene causing vasoconstriction and fibrosis is another mechanism proposed to mediate the adverse effect of metabolic acidosis on the progression of CKD $[9,25]$. Further, in a retrospective analysis of a large cohort study of patients with CKD, a serum bicarbonate level of $<22$ $\mathrm{mEq} / \mathrm{l}$ at baseline was associated with a $54 \%$ increased risk of progression (defined as either a decrease in eGFR by $50 \%$ or reaching an eGFR $<15 \mathrm{ml} / \mathrm{min} / 1.73 \mathrm{~m}^{2}$ ) compared with the reference group with a serum bicarbonate level of $25-26 \mathrm{mEq} / 1$ [26].

In previous studies in subtotally nephrectomized rats, administration of sodium bicarbonate increased blood pressure (as did the administration of sodium chloride) $[4,25]$. In one of these studies, the beneficial effect of alkali treatment on progression of GFR was evident only when the supplemental sodium-induced elevation in blood pressure was prevented pharmacologically [25]. In our meta-analysis, the sodium bicarbonate administered in the long-term trials had no adverse effect on blood pressure or cardiac function despite the fact that the majority of control subjects did not take matching sodium chloride. In this regard, in 3 out of the 4 long-term trials, the dose of sodium bicarbonate was modest $(0.5 \mathrm{mEq} / \mathrm{kg} /$ 
day, table 1). But even in the Mathur trial, in which the experimental subjects ingested $90-180 \mathrm{mEq} / \mathrm{day}$ of sodium bicarbonate, no adverse effects were noted. Similarly, in short-term studies, alkali administration did not influence blood pressure or body weight compared with controls (table 2). Remarkably, studies in animals and humans with sodium-sensitive hypertension have shown that non-chloride sodium salts, such as sodium bicarbonate, sodium citrate (citrate being metabolized to bicarbonate), sodium phosphate, and others, do not share the pressor effects of sodium chloride [27-31]. Administration of equivalent amounts of sodium salts attain similar degrees of sodium retention, weight gain, and inhibition of plasma renin and aldosterone levels, but only sodium chloride induces an increase in plasma volume and blood pressure. Also, non-sodium chloride salts (e.g. ammonium chloride, potassium chloride) do not have a pressor effect. The nature of the pressor effect of chloride when accompanying sodium remains unclear. The applicability of these observations to patients with CKD is currently unknown. In a previous small study of patients with advanced CKD, more sodium was excreted when administered as sodium bicarbonate than as sodium chloride (200 mEq/day, each for 4 days) and increases in weight and blood pressure occurred only during sodium chloride ingestion. However, these differential responses were dependent on the background presence of severe sodium chloride restriction (10 mEq/day) [18, 32, 33].

Although malnutrition is a potential consequence of chronic metabolic acidosis [3], we were unable to demonstrate a salutary effect of alkali therapy on body weight and serum albumin. Similarly, we did not discern a beneficial effect of alkali administration on urine protein excretion, in contrast to the experience in animal studies $[4,5]$.

The effects of alkali therapy on serum electrolytes were as expected in both short- and long-term studies. The significant decrease in serum potassium concentration effected by alkali therapy in long-term studies could confer benefit in view of the intrinsic or medication-induced (e.g. inhibitors of the renin-angiotensin-aldosterone system) impairment in potassium excretion associated with CKD.

The main limitations of the present analysis are the small number of trials with only a small population of analyzable patients, together with important clinical heterogeneity among the trials, including differences in CKD stages, control group treatment strategies, alkali therapy doses, and duration of follow-up. Further, the small sample size of most of the trials is also an impor- tant limitation of the available evidence. Because most of the control groups did not receive sodium-based placebo treatment, we can only speculate as to whether the observed benefit of alkali therapy on GFR was merely the reflection of extracellular-fluid volume expansion as a result of sodium retention rather than a putative salutary effect of alkali therapy on the kidney parenchyma, even though associated changes in body weight or blood pressure were lacking. Finally, for the assessment of change in GFR, we assumed that eGFR and calculated GFR (reported in different units) could be used interchangeably.

In conclusion, the present systematic review with meta-analyses suggests a potential benefit of alkali therapy on GFR in patients with CKD without any obvious harmful effects of associated volume expansion. This analysis calls for the design of a large randomized controlled trial in patients with advanced stage 4 CKD (GFR $<30 \mathrm{ml} /$ $\mathrm{min} / 1.73 \mathrm{~m}^{2}$ ) to examine the effect of sodium bicarbonate versus sodium chloride supplementation (with dose range finding under close monitoring) on a composite of major adverse kidney endpoints, including doubling of serum creatinine or annual GFR slope decline of $>3 \mathrm{ml} /$ $\mathrm{min} / 1.73 \mathrm{~m}^{2}$, kidney failure, or all-cause mortality. Such a study should also include a placebo arm that is supplemented with neither sodium bicarbonate nor sodium chloride, to control for the potential adversity of added sodium. However, until such a study is completed, we would recommend that clinicians consider administering modest doses of sodium bicarbonate or sodium citrate (if the former produces abdominal bloating), on the order of $0.5 \mathrm{mEq} / \mathrm{kg} / \mathrm{day}$, to patients with CKD and a serum bicarbonate $<22 \mathrm{mEq} / \mathrm{l}$, while cautiously monitoring for symptoms and signs of extracellular fluid volume expansion. In making this recommendation, we note the inexorable progression of many patients with CKD to end-stage kidney failure despite optimal contemporary management. We also find that the balance of the available evidence on alkali therapy in CKD from both randomized and nonrandomized studies is remarkably compelling in terms of efficacy, cost, and adverse effects. Indeed, future studies might support the administration of alkali therapy as an anti-progression modality at early stages of kidney disease, when serum bicarbonate is consistently within the normal range. Beyond the potential for retarding progression of CKD, such therapy might also afford attenuation of bone loss and improvement in muscle performance [34-36]. 


\section{Acknowledgements}

This work has been made possible in part through Dr. Susantitaphong's International Society of Nephrology funded Fellowship. This work was also supported in part by grant No. UL1 RR025752 from the National Center for Research Resources. The content is solely the responsibility of the authors and does not necessarily represent the official views of the National Center for Research Resources or the National Institutes of Health.

\section{Disclosure Statement}

The authors have no conflicts of interest to disclose.

\section{References}

1 Kraut JA, Kurtz I: Metabolic acidosis of CKD: diagnosis, clinical characteristics, and treatment. Am J Kidney Dis 2005;45:978-993.

2 K/DOQI, National Kidney Foundation. Clinical practice guidelines for nutrition in chronic renal failure. Am J Kidney Dis 2000; 35(suppl 2):S1-S140.

$\checkmark 3$ Kraut JA, Madias NE: Consequences and therapy of the metabolic acidosis of chronic kidney disease. Pediatr Nephrol 2011;26:1928.

4 Gadola L, Noboa O, Marquez MN, Rodriguez MJ, Nin N, Boggia J, Ferreiro A, Garcia S, Ortega V, Musto ML, et al: Calcium citrate ameliorates the progression of chronic renal injury. Kidney Int 2004;65:1224-1230.

$\checkmark 5$ Nath KA, Hostetter MK, Hostetter TH: Pathophysiology of chronic tubulo-interstitial disease in rats. Interactions of dietary acid load, ammonia, and complement component C3. J Clin Invest 1985;76:667-675.

-6 Torres VE, Mujwid DK, Wilson DM, Holley $\mathrm{KH}$ : Renal cystic disease and ammoniagenesis in Han:SPRD rats. J Am Soc Nephrol 1994;5:1193-1200.

7 Throssell D, Brown J, Harris KP, Walls J: Metabolic acidosis does not contribute to chronic renal injury in the rat. Clin Sci (Lond) 1995;89:643-650

$>8$ Jara A, Felsenfeld AJ, Bover J, Kleeman CR: Chronic metabolic acidosis in azotemic rats on a high-phosphate diet halts the progression of renal disease. Kidney Int 2000;58: 1023-1032.

-9 Phisitkul S, Khanna A, Simoni J, Broglio K, Sheather S, Rajab MH, Wesson DE: Amelioration of metabolic acidosis in patients with low GFR reduced kidney endothelin production and kidney injury, and better preserved GFR. Kidney Int 2010;77:617-623.

- 10 Mahajan A, Simoni J, Sheather SJ, Broglio KR, Rajab MH, Wesson DE: Daily oral sodium bicarbonate preserves glomerular filtration rate by slowing its decline in early hypertensive nephropathy. Kidney Int 2010;78: 303-309.

-11 De Brito-Ashurst I, Varagunam M, Raftery MJ, Yaqoob MM: Bicarbonate supplementation slows progression of CKD and improves nutritional status. J Am Soc Nephrol 2009; 20:2075-2084.

$\checkmark 12$ Menon V, Tighiouart H, Vaughn NS, Beck GJ, Kusek JW, Collins AJ, Greene T, Sarnak
MJ: Serum bicarbonate and long-term outcomes in CKD. Am J Kidney Dis 2010;56: 907-914.

13 Roderick P, Willis NS, Blakeley S, Jones C, Tomson C: Correction of chronic metabolic acidosis for chronic kidney disease patients. CochraneDatabaseSystRev2007:CD001890.

14 Alkali therapy to slow down progression of CKD (www2.niddk.nih.gov/KUH/KUH Home/KRND.htm).

15 Jadad AR, Moore RA, Carroll D, Jenkinson C, Reynolds DJ, Gavaghan DJ, McQuay HJ: Assessing the quality of reports of randomized clinical trials: is blinding necessary? Control Clin Trials 1996; 17:1-12.

-16 Seabra VF, Alobaidi S, Balk EM, Poon AH, Jaber BL: Off-pump coronary artery bypass surgery and acute kidney injury: a metaanalysis of randomized controlled trials. Clin J Am Soc Nephrol 2010;5:1734-1744.

$\checkmark 17$ DerSimonian R, Laird N: Meta-analysis in clinical trials. Control Clin Trials 1986;7: 177-188.

18 Husted FC, Nolph KD: $\mathrm{NaHCO}_{3}$ and $\mathrm{NaCl}$ tolerance in chronic renal failure. II. Clin Nephrol 1977;7:21-25.

19 Passfall J, Pai J, Spies KP, Haller H, Luft FC: Effect of water and bicarbonate loading in patients with chronic renal failure. Clin Nephrol 1997;47:92-98.

20 Mathur RP, Dash SC, Gupta N, Prakash S, Saxena S, Bhowmik D: Effects of correction of metabolic acidosis on blood urea and bone metabolism in patients with mild to moderate chronic kidney disease: a prospective randomized single blind controlled trial. Ren Fail 2006;28:1-5.

21 Disthabanchong S, Treeruttanawanich A: Oral sodium bicarbonate improves thyroid function in predialysis chronic kidney disease. Am J Nephrol 2010;32:549-556.

22 Stevens LA, Coresh J, Greene T, Levey AS: Assessing kidney function - measured and estimated glomerular filtration rate. N Engl J Med 2006;354:2473-2483.

23 Levey AS, Coresh J: Chronic kidney disease. Lancet 2012;379:165-180.

24 Voss D, Hodson E, Crompton C: Nutrition and growth in kidney disease: CARI guidelines. Aust Fam Physician 2007;36:253-254.

25 Phisitkul S, Hacker C, Simoni J, Tran RM, Wesson DE: Dietary protein causes a decline in the glomerular filtration rate of the rem- nant kidney mediated by metabolic acidosis and endothelin receptors. Kidney Int 2008; 73:192-199.

26 Shah SN, Abramowitz M, Hostetter TH, Melamed ML: Serum bicarbonate levels and the progression of kidney disease: a cohort study. Am J Kidney Dis 2009;54:270-277.

27 Whitescarver SA, Ott CE, Jackson BA, Guthrie GP Jr, Kotchen TA: Salt-sensitive hypertension: contribution of chloride. Science 1984;223:1430-1432.

28 Passmore JC, Whitescarver SA, Ott CE, Kotchen TA: Importance of chloride for deoxycorticosterone acetate-salt hypertension in the rat. Hypertension 1985;7:I115-I120.

29 Berghoff RS Geraci AS: The influence of sodium chloride on blood pressure. III Med J 1929;56:395-397.

30 Shore AC, Markandu ND, MacGregor GA: A randomized crossover study to compare the blood pressure response to sodium loading with and without chloride in patients with essential hypertension. J Hypertens 1988;6: 613-617.

-31 Kurtz TW, Al-Bander HA, Morris RC Jr: 'Salt-sensitive' essential hypertension in men. Is the sodium ion alone important? $\mathrm{N}$ Engl J Med 1987;317:1043-1048.

$>32$ Husted FC, Nolph KD, Maher JF: $\mathrm{NaHCO}_{3}$ and $\mathrm{NaCl}$ tolerance in chronic renal failure. J Clin Invest 1975;56:414-419.

33 Luft FC, Zemel MB, Sowers JA, Fineberg NS, Weinberger MH: Sodium bicarbonate and sodium chloride: effects on blood pressure and electrolyte homeostasis in normal and hypertensive man. J Hypertens 1990;8:663-670.

>34 Dawson-Hughes B, Harris SS, Palermo NJ, Castaneda-Sceppa C, Rasmussen HM, Dallal GE: Treatment with potassium bicarbonate lowers calcium excretion and bone resorption in older men and women. J Clin Endocrinol Metab 2009;94:96-102.

35 Dawson-Hughes B, Castaneda-Sceppa C, Harris SS, Palermo NJ, Cloutier G, Ceglia L, Dallal GE: Impact of supplementation with bicarbonate on lower-extremity muscle performance in older men and women. Osteoporos Int 2010;21:1171-1179.

$>36$ Sahni V, Rosa RM, Batlle D: Potential benefits of alkali therapy to prevent GFR loss: time for a palatable 'solution' for the management of CKD. Kidney Int 2010;78:10651067. 